\title{
Evaluation of Bone Density in Ankylosing Spondylitis Patient on Biologic Agents in Erbil City Case Control Study Mohammed Ibrahim Rasul (MBChB,MSc) ${ }^{1}$ and Shwan Kader $\operatorname{Media}(\mathrm{MBChB}, \mathrm{PhD})^{2}$
}

\author{
${ }^{1}$ Menistrey of Health, Erbil ,Iraq \\ ${ }^{2}$ College of Medicine, Hawler Medical University, Erbil ,Iraq \\ Correspondence Address: \\ Mohammed Ibrahim Rasul \\ Menistrey of Health , Erbil ,Iraq \\ email: shahenallany@yahoo.com
}

Received: 6 November 2020

Revised: 18 December 2020

Accepted: 26 January 2021

Published: 25 June 2021

Diyala Medical Journal 2021:20(2): 82- 93

\section{Abstract}

Background: Ankylosing spondylitis is a chronic autoimmune inflammatory disease, mostly affect young men. Reduced bone density is the most common complication in ankylosing spondylitis, since reduced bone density occurs in most of the patients. Assessment of bone density in the early stages of the disease by using X- ray absorptiometry is essential. Objective: To determine and evaluate the bone mineral density of ankylosing spondylitis patients compared healthy to control group.

Patients and Methods: This is a cross-sectional case control study of 50 patients with ankylosing spondylitis according to the Modified New York criteria and 50 healthy control group. The data were collected including socio demographic information of all patients (age, gender, medical history); systemic diseases type of biology treatment, using supplements, duration of ankylosing spondylitis, regular exercise, and smoking. The body mass index was calculated. Bone mineral density of the lumbar spine (L1-L4), and the left femoral neck were measured by using a dual energy $\mathrm{x}$-ray absorptiometry. Statistical analysis was done by using a statistical package for social sciences (SPSS) version 22; Fisher's exact, and Student's t tests were used to compare two means. A $p$ value of $\leq 0.05$ was considered statistically significant.

Results: The prevalence of osteoporosis and osteopenia among patients group according to Tspine score were $12 \%$ and $42 \%$ respectively, compared with $0 \%$ and $26 \%$ respectively among the control group $(\mathrm{p}=0.002)$ which was statistically significant. According to the T-left femur none patients group and the control group had osteoporosis, but $46 \%$ of the cases had osteopenia, compared with $8 \%$ of the controls which was statistically significant. There was a 
significant but non-consistent association between the disease duration and the osteoporosis, and osteopenia in spine and femur. The prevalence of osteopenia and osteoporosis in the spine and femur were highest among those with low body mass index.

Conclusion: Osteoporosis and osteopenia are common among patients with ankylosing spondylitis. In the early stage of disease osteoporosis can occur. The osteoporosis of the spine is more common than in the femur. Osteoporosis related to the duration of the diseases and body mass of the patient.

Keywords: Dual energy x-ray absorbiometry (DEXA); Ankylosing spondylitis; Osteoporosis; osteopenia; Bone mineral density

\section{Introduction}

Ankylosing spondylitis (AS) is a chronic auto immune inflammatory rheumatic disease, that involves sacroiliac joint and spine, vertebra and intervertebral disc causing syndesmophyte formation and reduced back mobility, mostly affect young male[1,2].

The early presentation of ankylosing spondylitis starts with low back pain and stiffness in most of the cases [3-7]. It is uncommon for ankylosing spondylitis to start before the age of 45 years of age [8]. As a consequence of this, there will be a reduced range of movement in the lower back, changes in the spine curvature can be seen on physical examination of the patient with AS. Other findings of ankylosing spondylitis patient are increased kyphosis in the thoracic area and loss of lordosis in lumbar and cervical area with abnormal hip flexion and pain and stiffness of the joints other than the low back [7].

There are two enhanced but opposite bone remodeling process that occurs within the spine of patients with AS; which are pathologic new bone formation in the cortical zone of the vertebrae the zygoapophyseal joints, and the ligamentous apparatus with excessive loss of trabecular bone in the center of the vertebral body leading to osteoporosis (OP).A previous study found that osteoporosis and osteopenia incidence is higher in AS patients compared with age and gender healthy controlled. Also AS patients have significantly lower bone mineral density (BMD) [1,2].

The incidence of osteoporosis between $18.7 \%$ and $62 \%$, and it is the most common complications of AS. The prevalence of osteoporosis is higher in male, and increases with increasing patient's age and disease duration [7]. Osteoporosis may also be seen in mild AS and in the early disease process [2,9].Vertebral fractures are another complication of AS, which is complicated by neurological injuries $[10,11]$.

The radiography is relatively insensitive in evaluating skeletal bone changes because $50 \%$ of the spine bone density has to be lost before demineralization become apparent on standard radiography. Patients who had longstanding ankylosing spondylitis the reduced bone density occur frequently. The sacroiliac joint is the first site in which radiological change occurred in ankylosing spondylitis. These changes need time to develop and sometimes take years before radiological findings become apparent. The $\mathrm{x}$-ray may be 
used to diagnose ankylosing spondylitis; MRI and CT-scan are no so valuable much and not routinely used. Dual Energy X-ray Absorption (DEXA) is the most reliable and dependable method for measurement of BMD [12].

The purpose of the current study was to evaluate the bone mass density of ankylosing spondylitis patient compared with the healthy control group.

\section{Patients and Methods}

This cross sectional case control study was conducted in the Hawler Teaching Hospital Department of Rheumatology. The study included 50 cases with AS and 50 healthy, socioeconomic matched controls subjects. The study protocol was approved by the ethical committee at the Kurdistan board for medical specialist. Informed consent was signed from the patients after a complete explanation of the aim of the study, and the patients data were kept confidential. Inclusion criteria including ankylosing spondylitis patients according to the modified New York criteria [13].

Exclusion criteria include, inflammatory bowel disease, psoriasis thyroid disease, pregnancy, other secondary cases that predispose to osteoporosis especially drugs, for example steroids, and disease modifying drugs were excluded from the study.

The consent was obtained according to the declaration of Helsinki physical examination and questioners. The data were collected from October 2019 -January 2020 including socio demographic variables of all patients; age, gender, and past medical history. Systemic disease type of biology treatment, using supplements duration of AS, regular exercise, smoking, were included in this study.

The weight and height were addressed in light clothes and without wearing shoes. Body mass index (BMI) was calculated from the weight and height recorded while performing DEXA scan and based on the formula weight $(\mathrm{kg}) /[\text { height }(\mathrm{m})]^{2}$. The standard categorization of BMI by CDC [14], 18.5 was regarded as Underweight, normal as 18.5-24.9, over weight as 25.0- 29.9, and 30.0 and above as obese morbidity.

Bone mineral density BMD of the lumbar spine region anteroposterior view (AP) in (vertebrae L1 to L4), and the neck of left hip femur were measured using a DXA scanner. Following World Health Organization (WHO) definitions of osteopenia and osteoporosis were used: osteopenia, T-score $<-1$ to $>-2.5 \mathrm{SD}$ (compared to the young normal mean), and osteoporosis, T-score $\leq$ 2.5 SD. The lowest value of bone mineral density BMD measured in the lumber spine, femoral neck or total hip was used [15]. For that patient with the age of fewer than 50 a Zscore $\leq-2.0 \mathrm{SD}$ (compared to the matched age) was considered to be below the expected range for age [16]. For the purpose of calculation of $\mathrm{T}$-score and $\mathrm{Z}$-score the BMD value of patient were compared with reference values provided by the DEXA scanner.

\section{Statistical analysis}

Data were analyzed using the statistical package for social science (SPSS, version 25). Chi square test of association was used to compare proportions. Fisher's exact test was used when the expected count of more than $20 \%$ of the cells of the table was less than 5. For comparison of two mean 
Student's t-test was used. Variables significantly were found to be associated with low bone mineral density were entered into a binary logistic regression model. A $\mathrm{p}$ value of $\leq 0.05$ was considered statistically significant.

\section{Results}

Fifty cases with ankylosing spondylitis were compassed in the study, in addition to 50 persons with no such disease. It is evident in table 1 that the mean age \pm SD of the cases was $37.56 \pm 9.92$ years which was significantly $(\mathrm{p}<0.001)$ higher than that of the control (31.18 \pm 6.62 years). The table shows also that $42 \%$ of the cases were aged
40 years or more compared with $10 \%$ of the controls $(\mathrm{p}=0.003)$. The majority $(78 \%)$ of the sample were males, but there was no significant difference between the two groups regarding the gender distribution $(\mathrm{p}=0.629)$. It is evident in the table that $18 \%$ of the cases had systemic diseases compared with $2 \%$ of the controls $(p=0.008)$. No significant differences were detected between the two groups regarding practicing exercise $(\mathrm{p}=$ $0.229)$ and smoking $(p=0.656)$. The proportion of the controls who used to take supplements was $72 \%$ which was statistically significantly $(\mathrm{p}=0.039)$ higher than the proportion between the cases (52\%).

Table (1): Basic characteristics of the studied sample

\begin{tabular}{|c|c|c|c|c|c|c|c|}
\hline & \multicolumn{2}{|c|}{ 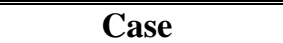 } & \multicolumn{2}{|c|}{ Control } & \multicolumn{2}{|c|}{ Total } & \multirow[b]{2}{*}{$\mathbf{P}$} \\
\hline & No. & $(\%)$ & No. & $(\%)$ & No. & $(\%)$ & \\
\hline \multicolumn{8}{|l|}{ Age } \\
\hline $2<30$ & 12 & $\begin{array}{l}(24.0) \\
\end{array}$ & 20 & $\begin{array}{l}(40.0) \\
\end{array}$ & 32 & $\begin{array}{l}(32.0) \\
\end{array}$ & \\
\hline $30-39$ & 17 & (34.0) & 25 & (50.0) & 42 & (42.0) & \\
\hline $40-49$ & 16 & $(32.0)$ & 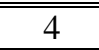 & $(8.0)$ & 20 & (20.0) & \\
\hline$\geq 50$ & 5 & $(10.0)$ & 1 & $(2.0)$ & 6 & $(6.0)$ & $0.003^{*}$ \\
\hline Mean( $( \pm$ SD) & 37.56 & $( \pm 9.92)$ & 31.18 & $( \pm 6.62)$ & & & $<0.001 \dagger$ \\
\hline \multicolumn{8}{|l|}{ Gender } \\
\hline Male & 38 & $\overline{(76.0)}$ & 40 & $(80.0)$ & 78 & (78.0) & \\
\hline Female & 12 & $(24.0)$ & 10 & $(20.0)$ & 22 & $(22.0)$ & $0.629 * *$ \\
\hline \multicolumn{8}{|c|}{ Systemic disease } \\
\hline Yes & 9 & (18.0) & 1 & $(2.0)$ & 10 & (10.0) & \\
\hline No & 41 & $(82.0)$ & 49 & (98.0) & 90 & (90.0) & $0.008^{* *}$ \\
\hline \multicolumn{8}{|c|}{ Regular exercise } \\
\hline Yes & 30 & (60.0) & 24 & (48.0) & 54 & $(54.0)$ & \\
\hline No & 20 & $(40.0)$ & 26 & $(52.0)$ & 46 & $(46.0)$ & $0.229 * *$ \\
\hline \multicolumn{8}{|l|}{ Smoking } \\
\hline Yes & 13 & (26.0) & 15 & (30.0) & 28 & (28.0) & \\
\hline No & 37 & $(74.0)$ & 35 & (70.0) & 72 & $(72.0)$ & $0.656^{* *}$ \\
\hline \multicolumn{8}{|l|}{ Supplement } \\
\hline Yes & 26 & $\begin{array}{l}(52.0) \\
\end{array}$ & 36 & $\begin{array}{l}(72.0) \\
\end{array}$ & 62 & $(62.0)$ & \\
\hline No & 24 & $(48.0)$ & 14 & $(28.0)$ & 38 & $38.0)$ & $0.039 * *$ \\
\hline Total & 50 & (100.0) & 50 & (100.0) & 100 & (100.0) & \\
\hline
\end{tabular}

${ }^{*}$ Fisher's exact test. ${ }^{* *}$ Chi square test. $\dagger \mathrm{t}$-test

According to the $\mathrm{t}$-spine scores, the prevalence of osteopenia and osteoporosis among cases were $42 \%$ and $12 \%$ respectively, compared with $0 \%$ and $26 \%$ respectively among the controls $(\mathrm{p}=0.002)$. According to the t-left femur scores, none of 
the patients had osteoporosis, but $46 \%$ of the the controls $(\mathrm{p}<0.001)$ as presented in Table cases had osteopenia, compared with $8 \%$ of

Table (2): Prevalence of reduced bone mineral density among cases and controls

\begin{tabular}{|l||c|c|c|c|c|c|c||}
\hline \multicolumn{1}{|c|}{} & \multicolumn{2}{c|}{ Case } & \multicolumn{2}{c||}{ Control } & \multicolumn{2}{c|}{ Total } & \\
\hline \hline & No. & $(\%)$ & No. & $(\%)$ & No. & (\%) & P \\
\hline \hline t-spine & & & & & & & \\
\hline \hline Osteoporosis & 6 & $(12.0)$ & 0 & $(0.0)$ & 6 & $(6.0)$ & \\
\hline \hline Osteopenia & 21 & $(42.0)$ & 13 & $(26.0)$ & 34 & $(34.0)$ & \\
\hline Normal & 23 & $(46.0)$ & 37 & $(74.0)$ & 60 & $(60.0)$ & $0.002^{*}$ \\
\hline \hline t-left femur & & & & & & & \\
\hline Osteopenia & 23 & $(46.0)$ & 4 & $(8.0)$ & 27 & $(27.0)$ & \\
\hline \hline Normal & 27 & $(54.0)$ & 46 & $(92.0)$ & 73 & $(73.0)$ & $<0.001$ \\
\hline \hline Total & 50 & $(100.0)$ & 50 & $(100.0)$ & 100 & $(100.0)$ & \\
\hline
\end{tabular}

Table (3) shows that, among the cases, the more the age, the more the prevalence of osteoporosis except for the age group 40-49 years where the prevalence was $0 \%(\mathrm{p}=$ 0.003). There was significant but nonconsistent association between the disease duration and the prevalence, where it evident that the prevalence was $25 \%$ when the duration was less than 5 years, and it was $18.2 \%$ when the duration was 15 years or more, while it was $0 \%$ in the other duration categories $(\mathrm{p}=0.038)$. The prevalence of osteoporosis was $30 \%$ among those with normal BMI, and it was $0 \%$ among those with a BMI of $\geq 35 \mathrm{Kg} / \mathrm{m}^{2}(\mathrm{p}=0.003)$. No significant association was detected between the $\mathrm{t}$-spine scores with gender $(\mathrm{p}=0.898)$, regular exercise $(\mathrm{p}=0.556)$, smoking $(\mathrm{p}$ $>0.999)$, and taking supplements $(\mathrm{p}=0.790)$.

Table (3): Prevalence of reduced bone mineral density (assessed by t-spine scores) by the studied factors among cases

\begin{tabular}{|c|c|c|c|c|c|c|c|}
\hline & \multicolumn{6}{|c|}{ t-spine scores categories } & \multirow[b]{3}{*}{$\mathbf{P}$} \\
\hline & \multicolumn{2}{|c|}{ Osteoporosis } & \multicolumn{2}{|c|}{ Osteopenia } & \multicolumn{2}{|c|}{ Normal } & \\
\hline & No. & $(\%)$ & No. & $(\%)$ & No. & $(\%)$ & \\
\hline \multicolumn{8}{|l|}{ Age } \\
\hline$<30$ & 1 & (8.3) & 9 & $75.0)$ & 2 & (16.7) & \\
\hline $30-39$ & 3 & $(17.6)$ & 8 & $(47.1)$ & 6 & (35.3) & \\
\hline $40-49$ & 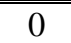 & (0.0) & 3 & (18.8) & 13 & (81.3) & \\
\hline$\geq 50$ & 2 & $(40.0)$ & 1 & $(20.0)$ & 2 & $(40.0)$ & $0.003 *$ \\
\hline \multicolumn{8}{|l|}{ Gender } \\
\hline Male & 5 & $(13.2)$ & 15 & $(39.5)$ & 18 & $(47.4)$ & \\
\hline Female & 1 & (8.3) & 6 & $(50.0)$ & 5 & $(41.7)$ & 0.898* \\
\hline \multicolumn{8}{|l|}{ Duration } \\
\hline$<5$ & 4 & $(25.0)$ & 7 & $(43.8)$ & 5 & $(31.3)$ & \\
\hline $5-9$ & 0 & $(0.0)$ & 7 & $(50.0)$ & 7 & $(50.0)$ & \\
\hline $10-14$ & 0 & (0.0) & 6 & $(66.7)$ & 3 & (33.3) & \\
\hline$\geq 15$ & 2 & $(18.2)$ & 1 & $(9.1)$ & 8 & $(72.7)$ & $0.038^{*}$ \\
\hline \multicolumn{8}{|l|}{ BMI } \\
\hline$<25$ & 3 & $(30.0)$ & 4 & $(40.0)$ & 3 & $(30.0)$ & \\
\hline
\end{tabular}


Evaluation of Bone Density in Ankylosing Spondylitis Patient on Biologic Agents in Erbil City Case Control Study

\begin{tabular}{|c|c|c|c|c|c|c|c|}
\hline $25-29$ & 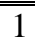 & (6.7) & 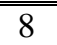 & (53.3) & 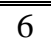 & (40.0) & \\
\hline $30-34$ & 2 & $(13.3)$ & 9 & (60.0) & 4 & $(26.7)$ & \\
\hline$\geq 35$ & 0 & $(0.0)$ & 0 & $(0.0)$ & 10 & $(100.0)$ & $0.003 *$ \\
\hline \multicolumn{8}{|c|}{ Regular exercise } \\
\hline Yes & 5 & $(16.7)$ & 12 & $(40.0)$ & 13 & $(43.3)$ & \\
\hline No & 1 & $(5.0)$ & 9 & $(45.0)$ & 10 & $(50.0)$ & $0.556 *$ \\
\hline \multicolumn{8}{|l|}{ Smoking } \\
\hline Yes & 1 & $(7.7)$ & 6 & $(46.2)$ & 6 & (46.2) & \\
\hline No & 5 & $(13.5)$ & 15 & $(40.5)$ & 17 & $(45.9)$ & $>0.999 *$ \\
\hline \multicolumn{8}{|l|}{ Supplement } \\
\hline Yes & 4 & $(15.4)$ & 10 & $(38.5)$ & 12 & $(46.2)$ & \\
\hline No & 2 & $(8.3)$ & 11 & $(45.8)$ & 11 & $(45.8)$ & $0.790 *$ \\
\hline Total & 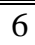 & $(12.0)$ & 21 & $(42.0)$ & 23 & (46.0) & \\
\hline
\end{tabular}

* Fisher's - exact test

In Table (4), the results of the cases were analyzed, where the prevalence of osteopenia (assessed by left femur $\mathrm{t}$ scores) was compared between the different categories of the studied factors. Among cases, the prevalence of osteopenia among females $(75 \%)$ was statistically significantly $(\mathrm{p}=$ 0.021) higher than the prevalence between

Table(4): Prevalence of osteopenia (assessed by left femur $t$ scores) among cases

\begin{tabular}{|c|c|c|c|}
\hline & \multicolumn{3}{|c|}{ Prevalence of osteopenia $\uparrow$} \\
\hline & \multicolumn{3}{|c|}{ Cases } \\
\hline & $\mathbf{N}$ & No. & $(\%)$ \\
\hline \multicolumn{4}{|l|}{ Age } \\
\hline $\begin{array}{c}<30 \\
30\end{array}$ & $\overline{12}$ & $\overline{\overline{77}}$ & $\begin{array}{c}(58.3) \\
\end{array}$ \\
\hline 30-39 & 17 & 10 & $(58.8)$ \\
\hline $40-49$ & 16 & 3 & $(18.8)$ \\
\hline$\geq \mathbf{5 0}$ & 5 & 3 & $\begin{array}{l}(60.0) \\
\end{array}$ \\
\hline P value & & & $0.059 *$ \\
\hline \multicolumn{4}{|l|}{ Gender } \\
\hline$\overline{\text { Male }}$ & 38 & $\overline{14}$ & (36.8) \\
\hline Female & 12 & $\overline{9}$ & $\begin{array}{l}(75.0) \\
\end{array}$ \\
\hline P value & & & 0.021 \\
\hline \multicolumn{4}{|c|}{ Duration of the disease } \\
\hline$<5$ & 16 & 7 & $\begin{array}{l}(43.8) \\
\end{array}$ \\
\hline $5-9$ & 14 & 7 & (50.0) \\
\hline $10-14$ & 9 & 4 & $(44.4)$ \\
\hline$\geq 15$ & 11 & 5 & $(45.5)$ \\
\hline P value & & & $>0.999 *$ \\
\hline \multicolumn{4}{|l|}{ BMI } \\
\hline$<25$ & 10 & 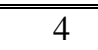 & (40.0) \\
\hline $25-29$ & 15 & 9 & (60.0) \\
\hline
\end{tabular}
$(60 \%)$ among those with a BMI of 25-29 and $30-34 \mathrm{Kg} / \mathrm{m}^{2}$ ( $\mathrm{p}=0.046$ ) but this association was not consistent as the prevalence was $40 \%$ among those with normal BMI, then increased to $60 \%$, then decreased to $10 \%$. All the other associations were not significant. 
Evaluation of Bone Density in Ankylosing Spondylitis Patient on Biologic Agents in Erbil City Case Control Study

\begin{tabular}{|c|c|c|c|}
\hline 30-34 & 15 & 99 & (60.0) \\
\hline$\geq 35$ & 10 & 1 & $(10.0)$ \\
\hline P value & & & 0.046* \\
\hline \multicolumn{4}{|c|}{ Regular exercise } \\
\hline Yes & 30 & 12 & $(40.0)$ \\
\hline No & 20 & 11 & $(55.0)$ \\
\hline P value & & & 0.297 \\
\hline \multicolumn{4}{|l|}{ Smoking } \\
\hline Yes & 13 & 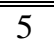 & (38.5) \\
\hline No & 37 & 18 & (48.6) \\
\hline P value & & & 0.526 \\
\hline \multicolumn{4}{|c|}{ Supplement } \\
\hline Yes & 26 & 12 & (46.2) \\
\hline No & 24 & 11 & (45.8) \\
\hline P value & & & 0.982 \\
\hline Total & 50 & 23 & (46.0) \\
\hline
\end{tabular}

* Fisher's exact test (the others are by the Chi square test). $\uparrow$ None of the patients was diagnosed as osteoporosis according to T-left femur scores

No statistically significant relation was determined between the prevalence of reduced bone mineral density with the type of treatment taken by the patients whether this

Table(5): Prevalence of reduced bone mineral density by type of treatment

\begin{tabular}{|c|c|c|c|c|c|c|c|}
\hline & \multicolumn{6}{|c|}{ Treatment } & \multirow[b]{3}{*}{$\overline{\mathbf{P}}$} \\
\hline & \multicolumn{2}{|c|}{ Etanarcept } & \multicolumn{2}{|c|}{ Infliximab } & \multicolumn{2}{|c|}{ "Adalimumab } & \\
\hline & No. & $(\%)$ & No. & $(\%)$ & No. & $(\%)$ & \\
\hline \multicolumn{8}{|l|}{ T-spine } \\
\hline Osteoporosis & 2 & $\begin{array}{l}(6.9) \\
\end{array}$ & 3 & (23.1) & $\overline{11}$ & (12.0) & \\
\hline Osteopenia & 12 & (41.4) & 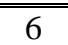 & (46.2) & 3 & (37.5) & \\
\hline Normal & 15 & (51.7) & 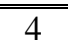 & (30.8) & 4 & $\overline{(50.0)}$ & $0.537 *$ \\
\hline \multicolumn{8}{|l|}{ T-left femur } \\
\hline Osteopenia & 13 & (44.8) & 7 & (53.8) & 3 & $(37.5)$ & \\
\hline Normal & 16 & $(55.2)$ & 6 & $(46.2)$ & 5 & $(62.5)$ & $0.791 *$ \\
\hline Total & 29 & $(100.0)$ & 13 & (100.0) & 8 & $(100.0)$ & \\
\hline
\end{tabular}

*By Fisher's exact test

The factors found to be significantly associated with the development of reduced bone mineral density (osteoporosis or osteopenia) were the disease ankylosing prevalence was assessed by the t-spine scores $(\mathrm{p}=0.537)$, or the $\mathrm{t}$-left femur scores $(\mathrm{p}=$ $0.791)$. spondylitis $(\mathrm{OR}=4.731, \mathrm{p}=0.002)$, BMI of $<25 \mathrm{Kg} / \mathrm{m}^{2}(\mathrm{OR}=16.97, \mathrm{p}=0.022)$, and BMI $30-34 \mathrm{Kg} / \mathrm{m}^{2}(\mathrm{OR}=18.49, \mathrm{p}=0.013)$ as presented in Table (6). 
Evaluation of Bone Density in Ankylosing Spondylitis Patient on Biologic Agents in Erbil City Case Control Study

Table(6): SPSS output for binary logistic regression analysis where the dependent variable is reduced bone mineral density

\begin{tabular}{|c|c|c|c|c|c|}
\hline & & & & \multicolumn{2}{|c|}{ 95\% C.I.for OR } \\
\hline & $\mathbf{B}$ & $\mathbf{P}$ & OR & Lower & Upper \\
\hline \multicolumn{6}{|l|}{ Group } \\
\hline Ankylosing spondylitis & 1.554 & 0.002 & 4.731 & 1.801 & 12.426 \\
\hline \multicolumn{6}{|l|}{ Controls (reference) } \\
\hline Age (years) & & 0.573 & & & \\
\hline \multicolumn{6}{|l|}{$<30$ (reference) } \\
\hline $30-39$ & 0.185 & 0.728 & 1.203 & 0.424 & 3.411 \\
\hline 440-49 & -0.695 & 0.393 & 0.499 & 0.101 & 2.458 \\
\hline$\geq 50$ & 0.755 & 0.492 & 2.129 & 0.246 & 18.388 \\
\hline BMI $\left(\mathrm{Kg} / \mathrm{m}^{2}\right)$ & & 0.051 & & & \\
\hline$<25$ & 2.832 & 0.022 & 16.977 & 1.507 & 191.286 \\
\hline $25-29$ & 2.122 & 0.080 & 8.350 & 0.775 & 90.014 \\
\hline $30-34$ & 2.918 & 0.013 & 18.499 & 1.832 & 186.799 \\
\hline \multicolumn{6}{|l|}{$\geq 35$ (reference) } \\
\hline Constant & -3.508 & 0.005 & 0.030 & & \\
\hline
\end{tabular}

\section{Discussion}

This study revealed that patients with AS are more susceptible to osteoporosis, but is often undiagnosed and untreated, this study also suggested that AS patients are at risk of osteoporosis and have lower B level in comparison to the control. The decreased bone density at the spine region and femur area is well demonstrated in AS. However, there has been wide variation in the prevalence of osteoporosis ranging from $18.7 \%$ and $62 \%$ [7]. We reported $\mathrm{A}$ significant reduction of the bone mineral density of AS patients at lumbar spine, and femur, as compared to the control group. In this study we observed that $12 \%$ of patients with ankylosing spondylitis had osteoporosis, $42 \%$ had osteopenia in the spine; where-as in the control group none had osteoporosis, 26 $\%$ had osteopenia in the spine. In the current study, a significant difference in the change in BMD was present at the femoral neck $(\mathrm{P}<$ $0.05)$; at the femoral neck we found none of the patients and control had osteoporosis but $46 \%$ of cases had osteopenia, compared with
$8 \%$ of the control group which was similar to the result, found by the Diab, 2018 [17]. This study recorded a significant reduction in BMD in both spine and femur in AS. There are several studies that examined bone mass in ankylosing spondylitis patients, the result was similar, showing that BMD is reduced in AS patients in comparison with controls, with some difference according to the duration of the disease.

The AS typically occurs in the third and fourth decade of life, many patients are younger than the traditional cohort of older patient with low, even patients who had AS for less than 10 years are at high risk for low bone mineral density [18], in the current study the more age the more prevalence of osteopenia the older age has been found to be at significant for low BMD in patients with AS compared with the control group.

In the present study osteopenia and osteoporosis in the lumbar spine were more common in men than in women and thus more men were diagnosed as osteoporotic but the difference was not significant.AS is 
usually diagnosed in the third and fourth decade of life, with male predominating in most population surveys, at a ratio of 5:1[19]. It is likely that the sex ratio is closer to the unity in reality, with males being prone to more severe disease [21] and to the development of osteopenia [22].This might be due to the natural protective effect of estrogen hormone against the occurrence of osteopenia more common in male AS than in females.

Furthermore, our AS patients with osteopenia was older, and had a longer disease duration than those without osteopenia.There was a significant but nonconsistent association between the disease duration and the prevalence of osteoporosis ( $\mathrm{p}=0.038$ ), which was agreed with thestudy done, by Donelly et al., who found that a significant reduction in the BMD at the neck of femur in patients with AS, and the reduction in proportion to the diseases duration and severity . They also found that the lumbar spine bone density was reduced in early disease, but in patients with advanced AS it was increased considerably [1].

In the present study, the osteopenia and osteoporosis in the lumber spine and osteopenia in the femoral neck are more common in thinner patients with AS, as has been found by another study. The correlation between BMD at the neck of femur and BMI was highly positive in cross sectional study conducted among post-menopausal women by Steinschneider et al [23].

Patient with low body mass index are more susceptible to developin osteopenia. In this study, the one of the factors found to be significantly associated with the development of a reduced BMD (osteoporosis or osteopenia), is low BMI, similar studies by Nguyen et al [24] and Baheiraei et al [25], also reported the consistent findings that lower BMI was associated with lower BMD.

In this study we found that osteoporosis in AS patients was more common in smokers than in non- smokers, but the difference was not statistically significant, and this finding was in agreement with that of Lorentzon et al [26], who reported that smokers had a significantly lower BMD on DEXA than nonsmokers. Cigarette smoking is a risk factor for osteoporosis and is related to a decreased of bone mass and increased risk of fractures [27].

In the current study it is found that regular exercise had no effect on BMD among patient with AS in spine and femur. It is accepted that weight bearing exercise improves bone mineral density. There is no current study to demonstrate the effect of exercise on BMD on patients with AS. However, improvement in physical function and disease activity has been noted in patients with AS who participated in the exercise program [28,29]. Recent guidelines also recommended consistent physical activity and stretching exercise in patient with ankylosing spondylitis [30].Many studies regarding physical activity as part of the management of osteoporosis in postmenopausal women and thus may not fully generalized to the population of patients with AS. However, given the benefits in patients with AS coupled with the benefits of physical activity in osteoporosis treatment prevention can be achieved in other demographics.

Regarding the activity of the disease, biological drugs may prevent bone loss via a 
direct effect on bone metabolism and remodeling. It is well demonstrated that $\mathrm{TNF} \alpha$ induces differentiation of osteoclast precursors through a synergistic action with receptors activator of nuclear factor-kappa $\mathrm{B}$ ligand (RANKL) [31]. The balance between TNF superfamily molecule RANKL- , osteoprotogerin, osteoclastogenesis inhibitory factors, and TNF-related apoptosis inducing ligand to regulate bone metabolism and remodeling [32-34], there is no significant difference in BMD change in biologics responders and non-responders [35,36]. In this study we found that biologics therapy was not significantly affected BMD, sequential evaluation of BMD during biological therapy should help to illuminate their influence on bone density.

There was no significant relation detected between the prevalence of reduced bone mineral density with the type of treatment taken by the patients whether this prevalence was assessed. There is no enough evidence to support the use of TNF inhibitors for the sole purpose of prevention of osteoporosis and low bone mass density in patent with ankylosing spondylitis. However we have a low threshold to start TNF blocker in patient noted to have low BMD and active AS with close monitoring of low bone density and osteoporosis by DEXA scanning at two years intervals.

\section{Conclusions}

The prevalence of osteopenia and osteoporosis are high in patient with ankylosing spondylitis. Osteoporosis was often undiagnosed and untreated, especially in male patients with AS. Older age, long disease duration, and a low BMI an indicate increased risk of osteoporosis.

\section{Recommendations}

We recommend another study measuring BMD after1 year to see the effect of biology in BMD and comparing it with this data. Source of funding: No source of funding this is on my duty.

Ethical clearance: This study was approved by research ethical committee college of Medicine Hawler Medical University.

Conflict of interest:This research done by one researcher so no Conflict of Interest.

\section{References}

[1]Donnelly S, Doyle DV, Denton A, Rolfe I, McCloskey EV, Spector TD: Bone mineral density and vertebral compression fracture rates in ankylosing spondylitis. Ann Rheum Dis 1994, 53:117-121. 2.

[2]Mitra D, Elvins DM, Speden DJ, Collins AJ: The prevalence of vertebral fractures in mild ankylosing spondylitis and their relationship to bone mineral density. Rheumatology (Oxford, England) 2000, 39:85-89.

[3]Walsh NC, Crotti TN, Goldring SR, Gravallese EM. Rheumatic diseases: the effects of inflammation on bone. Immunol Rev. 2005; 208:228-51.

[4]Wendling D. Bone loss in ankylosing spondylitis: Can we put the puzzle together? J Rheumatol. 2005; 32:1184-86.

[5]Sieper J, Braun J, Rudwaleit M, Boonen A, Zink A. Ankylosing spondylitis: an overview. Ann Rheum Dis. 2002;61 (Suppl 3): iii8 -iii18.

[6]Toussirot E, Wendling D. Bone mass in ankylosing spondylitis. Clin Exp Rheumatol. 2000;18 (Suppl 21): S16-S20. 
[7]Bessant $R$ and Keat A. How should clinicians manage osteoporosis in ankylosing spondylitis? J Rheumatol. 2002 Jul; 29(7):1511-9.

[8]Olivieri I, Salvarani C, Cantini F, Ciancio G, Padula A. Ankylosing spondylitis and undifferentiated spondyloarthropathies: a clinical review and description of a disease subset with older age at onset. Curr Opin Rheumatol. 2001; 13:280-4.

[9] Will R, Palmer R, Bhalla AK, Ring F, Calin A: Osteoporosis in early ankylosing spondylitis: a primary pathological event? Lancet 1989, 2:1483-1485.

[10]Cooper C, Carbone L, Michet CJ, Atkinson EJ, O'Fallon WM, Melton LJ: Fracture risk in patients with ankylosing spondylitis: a population based study. Journal Rheumatol 1994, 21:1877-1882.

[11] Westerveld LA, Verlaan JJ, Oner FC: Spinal fractures in patients with ankylosing spinal disorders: a systematic review of the literature on treatment, neurological status and complications. Eur Spine J 2009, 18:145156.

[12]Mazess RB. Bone densitometry of the axial skeleton. Orthop Clin North Am. 1990; 21: 51-63.

[13]Van der Linden S, Valkenburg HA, Cats A: Evaluation of diagnostic criteria for ankylosing spondylitis. A proposal for modification of the New York criteria. Arthritis Rheum 1984, 27:361-368.

[14]Centers for Disease Control and Prevention. Credible health information, 2009, http://www.cdc.gov/healthyweight/ assessing/bmi/adult BMI/index.html.

[15]Assessment of fracture risk and its application to screening for postmenopausal osteoporosis. Report of a WHO Study Group.
World Health Organ Tech Rep Ser 1994, 843:1-129.

[16] Baim S, Leonard MB, Bianchi ML, Hans DB, Kalkwarf HJ, Langman CB, Rauch F: Official Positions of the International Society for Clinical Densitometry and executive summary of the 2007 ISCD Pediatric Position Development Conference. J Clin Densitom 2008, 11:6-21.

[17]Diab AS. The impact of osteoporosis in patients with ankylosing spondylitis and its relationship to physical activity. Med J Babylon 2018; 15:32-8.

[18] Van Der Weijden MAC, Claushuis TAM, Nazari T, Lems WF, Dijkmans BAC, Van Der Horst- Bruinsma IE. High prevalence of low bone mineral density in patients within 10 years of onset of ankylosing spondylitis: A systematic review. Clin Rheumatol. 2012:1529-35.

[19]Gran JT, Husby G, Hordvik M. Prevalence of ankylosing spondylitis in males and females in a young middle-aged population of Troms $\emptyset$, northern Norway. Ann Rheum Dis 1985; 44:359-67.

[20]Silman AJ, Hochberg MC. Epidemiology of the rheumatic diseases. Oxford: Oxford University Press; 1993.

[21]Devogelaer J-P, Maldague B, Malghem J, Nagant De Euxchaisnes C. Appendicular and vertebral bone mass in ankylosing spondylitis. A comparison of plain radiographs with single- and dual-photon absorptiometry and with quantitative computed tomography. Arthritis Rheum 1992; 35:1062-7.

[22]Tenenhouse A, Joseph L, Kreiger N, et al. Estimation of the prevalence of low bone density in Canadian women and men using a population-specific DXA reference standard: 
the Canadian Multicentre Osteoporosis Study (CaMos). Osteoporosis Int 2000; 11:897-904. [23] Steinschneider. M, Hagag. P, Rapoport. M. J, and Weiss. M, "Discordant effect of body mass index on bone mineral density and speed of sound," BMC Musculoskeletal Disorders, vol. 4, article 1, pp. 1-6, 2003.

[24] Nguyen T. V, Center J. R., and Eisman, J. A. "Osteoporosis in elderly men and women: effects of dietary calcium, physical activity, and body mass index," Journal of Bone and Mineral Research, vol. 15, no. 2, pp. 322-331, 2000.

[25] Baheiraei A, Pocock N. A., Eisman J. A., Nguyen N. D., and Nguyen T. V., "Bone mineral density, body mass index and cigarette smoking among Iranian women: implications for prevention," BMC Musculoskeletal Disorders,2005 vol. 6, article 34.

[26]Lorentzon M, Mellström D, Haug E, Ohlsson C. Smoking is associated with lower bone mineral density and reduced cortical thickness in young men. $\mathrm{J}$ Clin Endocrinol Metab. 2007; 92:497-503.

[27] Kline J, Tang A, Levin B. Smoking, alcohol and caffeine in relation to two hormonal indicators of ovarian age during the reproductive years. Maturitas. 2016; 92:115122.

[28] Liang $\mathrm{H}$, Zhang $\mathrm{H}$, Ji $\mathrm{H}$, Wang $\mathrm{C}$. Effects of home-based exercise intervention on health-related quality of life for patients with ankylosing spondylitis: a meta-analysis. Clin Rheumatol. 2015; 34:1737-44.

[29]O'Dwyer T, O'Shea F, Wilson F. Exercise therapy for spondyloarthritis: A systematic review. Rheumatol Int. 2014; 34:887-902.
[30]Millner, JR., Barron, JS., Beinke, KM., Butterworth, RH., Chasle, BE., Dutton, LJ., et al. Semin Arthritis Rheum [Internet]. Vol. 45. Elsevier; 2016. Exercise for ankylosing spondylitis: An evidence-based consensus statement; p. 411-27.

[31]Li P, Schwarz EM, O’Keefe RJ, Ma L, Looney RJ, Ritchlin CT, et al. Systemic tumor necrosis factor alpha mediates an increase in peripheral CD11bhigh osteoclast precursors in tumor necrosis factor alphatransgenic mice. Arthritis Rheum. 2004;50(1):265-76.

[32] Hofbauer LC, Heufelder AE. The role of osteoprotegerin and receptor activator of nuclear factor kappaB ligand in the pathogenesis and treatment of rheumatoid arthritis. Arthritis Rheum. 2001;44(2):253-9. [33]Gravallese EM, Goldring SR. Cellular mechanisms and the role of cytokines in bone erosions in rheumatoid arthritis. Arthritis Rheum. 2000;43(10):2143-51.

[34]Kong YY, Boyle WJ, Penninger JM. Osteoprotegerin ligand: a regulator of immune responses and bone physiology. Immunol Today. 2000;21(10):495-502.

[35]Guler-Yuksel M, Bijsterbosch J, Goekoop-Ruiterman YP, de Vries-Bouwstra JK, Hulsmans HM, de Beus WM, et al. Changes in bone mineral density in patients with recent onset, active rheumatoid arthritis. Ann Rheum Dis. 2008;67(6):823-8.

[36] Marotte H, Pallot-Prades B, Grange L, Gaudin P, Alexandre C, Miossec P. A 1-year case-control study in patients with rheumatoid arthritis indicates prevention of loss of bone mineral density in both responders and non responders to infliximab. Arthritis Res Ther. 2007;9(3): R61. 